\title{
Risk framing and business model adaptation: A conceptualization based on threat-rigidity theory
}

\author{
Camilla Aarøen \\ Norwegian School of Economics \\ Marcus Selart \\ Norwegian School of Economics
}

Corresponding author: Marcus Selart, Norwegian School of Economics,

Department of Strategy and Management, Helleveien 30, 5045 Bergen,

Norway, Marcus.Selart@nhh.no, +47 55959695 


\begin{abstract}
Firm leaders' inclination to adapt their business model is sensitive to how risk is framed (as an external threat or an opportunity) in the macro-economic environment. We apply threatrigidity theory to examine the relationship between risk framing and business model adaptation. We also investigate if emotionality has explanatory value for how managers adapt to business models. We test our hypotheses in a field experiment involving 134 Scandinavian managers. Here, we relate managers' inclinations to adapt to different business models to different risk scenarios. The results reveal that, in general, managers are more risk seeking in gain scenarios than in loss scenarios. This finding is in line with the threat-rigidity theory. Emotionality was found to relate more to risk aversion than to risk seeking in the domain of potential gain. We argue that emotionality has explanatory value for how managers adapt to business models, because emotions are key influences on risk perception.
\end{abstract}

Keywords: Emotionality, Risk perception, Business model adaptation, Threat-rigidity theory, Prospect theory 
Adapting the business model is a risky venture as there is no way of knowing whether one will succeed. Central themes in the field of strategy pertain to sustaining competitive advantage and creating value in firms and industries (Bashir \& Verma, 2019). The business model has become an essential tool in achieving these factors. A firm's business model is its strategy of how to create, deliver, and capture value. It is also a description of how processes and infrastructures in the firm are related. Research on business models has flourished in recent years. The business model concept appeals to both researchers and practitioners. The most significant development is the recognition that adapting, shaping, and renewing the business model is paramount for firms to create value on a continuous basis. Firms that have been successful for some time risk failing if they do not alter the business model to adapt to external changes (Achtenhagen et al., 2013; Bashir \& Verma, 2019; Demil \& Lecocq, 2010; McGrath, 2010; Teece, 2010). A large group of studies therefore report the effects of changes in the business model. An umbrella term for changes in the business model is business model adaptation, defined as the process by which firms actively align their business model to a changing environment (Saebi et al., 2017). However, business models are often challenging to alter. Characteristics within firms can make the business model rigid and inert (Achtenhagen et al., 2013; Andries et al., 2013; Bashir \& Verma, 2019; Doz \& Kosonen, 2010; McGrath, 2010; Sosna et al., 2010).

The rapid growth in the number of articles written about the business model concept demonstrates its importance as a relatively new unit of analysis, distinct from the product, firm, industry, or network (Chesbrough, 2010; Osterwalder, 2004; Osterwalder \& Pigneur, 2010; Zott et al., 201o; Zott et al., 2011). As business models have gained popularity as a topic for research, the focus in the literature has shifted from examining the static business model to exploring how business models change, evolve, and innovate over time (Saebi, et al., 2017). Changes in the business model can occur as business model learning, innovation, renewal, 
replication, erosion, life cycle, transformation, creation, and transformation (Bashir \& Verma, 2019; Cavalcante, et al., 2011; Teece, 2010; Casadesus-Masanell \& Zhu, 2013). Saebi et al. (2017) classify all these dynamics as business model adaptation, defined as "the process by which management actively aligns the firm's business model to a changing environment, for example, changes in the preferences of customers, supplier bargaining power, technological changes, competition, etc.". Drivers of business model adaptation are strictly external and include external stakeholders, changes in the competitive environment, and new opportunities brought about by new information and communication technologies (Saebi, et al., 2017). These drivers influence business model adaptation (Voelpel, et al., 2004; Pateli \& Giaglis, 2005; Ferreira, et al., 2013; Miller, et al., 2014).

Other research shows that rigid business models are related to firms' willingness to experiment (Andries, et al., 2013; Sosna, et al., 2010; McGrath, 2010) and firms' ability to develop organisational and leadership capabilities (Achtenhagen, et al., 2013; Bashir \& Verma, 2019; Doz \& Kosonen, 2010). Furthermore, path dependencies, which contribute to stability and operational efficiency, can cause business models to become inert over time (Saebi, et al., 2017). Adapting the business model can be a high-risk strategy (Pateli \& Giaglis, 2005). When the outcome is uncertain and business models may become inert, leaders and firms need strong incentives to adapt their business model.

Threat-rigidity theory suggests that people will exhibit rigidity, or an inability to act, when faced with economic adversity. According to the theory, people confronted with poor economic performance or threats in their environments will tend to act conservatively, looking inward and reacting by relying on existing routines (Shimizu, 2007).

We provide two contributions in this study. First, reviewing relevant literature on business model adaptation, we investigate the predictive capability of threat-rigidity theory. We sense 
that there exist a gap in the research literature, since there are no existing studies until today connecting business model adaptation with rigidity based on threat. Because the theoretical foundation for understanding business model adaptation is relatively weak, we consider the current study a pioneering effort. Second, we examine the extent to which emotionality as a trait has the capacity to influence the relationship between risk perception and business model adaptation - specifically, how emotionality relates to risk aversion and risk seeking in scenarios of potential gains and losses.

\section{Theoretical background}

\section{1 Risk perception as a driver of business model adaptation}

Adapting the business model is often a risky venture, and the likelihood of succeeding in doing so is low (Pateli \& Giaglis, 2005). It is therefore not surprising that business models often do not change once put in place. Findings from several contributions suggest that this inertia can be blamed on firms' unwillingness to experiment (Andries, et al., 2013), firms' lack of ability to develop leadership and organisational skills (Doz \& Kosonen, 2010; Achtenhagen, et al., 2013; Bashir \& Verma, 2019), and path dependencies in firms (Saebi, et al., 2017). In the face of this low likelihood of success and firm characteristics that prevent adaptation, what factors can prompt firms to adapt their business models?

In their classic threat-rigidity theory article, Staw et al. (1981) hypothesised that threats might lead organisations to, among other things, rely on prior knowledge, centralise authority, and increase efficiency, which results in constricted control, conservation of resources, and a restriction on information processing. When faced with perceived opportunity, firms are expected to have the ability and motivation to take more risks (Trimpop, 1994; Selart, 2010). Perceptions of opportunity are associated with higher levels of control, which should motivate firms to "initiate actions that might otherwise be perceived as too risky" (Chattopadhyay \& 
Huber, 2001). Researchers have found support for the validity of the threat-rigidity theory in the context of loss (Chattopadhyay \& Huber, 2001; Meschi \& Métais, 2015; Mcmanus \& Sharfman, 2017), but less proof exists of its legitimacy in the context of gain. Research finds that firms are more likely to pay higher premiums if acquisitions are framed as opportunities (Mcmanus \& Sharfman, 2017), but other than this, little proof exists.

H1. Managers are more likely to engage in business model adaptation in environments of perceived opportunity or potential gain than in environments of perceived threat or potential loss.

\subsection{Emotionality as a modifier of the relationship between risk perception and business}

\section{model adaptation}

High emotionality is characterised by a tendency to worry about minor matters, feeling empathetic towards others, and a propensity to share concerns (Lee \& Ashton, 2013). Individual differences associated with sentimentalities, such as experiences of anxiety, sentimentality, and empathy versus fearlessness, detachment, and independence, are assigned to the emotionality trait (Weller \& Tikir, 2011; de Vries, et al., 2009).

Emotionality influences risk-taking behaviour and is associated with higher risk perceptions (Weller \& Tikir, 2011). The emotionality trait has some similarities to the neuroticism trait, in which people who score high (i.e., highly neurotic people) show a tendency to be anxious, compulsive, defensive, and thin-skinned (McCrae \& Costa, 1987). The trait also relates to bad self-esteem and low self-efficacy (Judge, et al., 2002).

Several studies have found relationships among emotionality, risk taking, and risk perception, which implies that emotional individuals are less inclined to take risks. For example, emotionally stable individuals perceive risks as lower than emotionally unstable individuals 
(Fyhri \& Backer-Grøndahl, 2012). Emotionality is associated with a lower propensity to take risks in both the potential loss and the potential gain domains (Weller \& Thulin, 2012).

In general, emotionality appears to be connected with risk aversion and a higher-than-average risk perception. We assume that firms with risk-averse managers will be hesitant to implement changes in the domain of potential loss. However, higher perceptions of risk may make firms including managers with a high emotionality score less inclined to adapt business models when faced with opportunities as well. In summary, we predict that managers with a high emotionality score will act rigidly in both potential gain and potential loss domains. This prediction correlates with prospect theory in domains of potential gain and threat-rigidity theory in domains of potential loss. In line with these assumptions and arguments, we propose the following hypotheses:

H2a. The higher the emotionality score, the less likely the leader is to propose business model adaptation in the domain of potential gain.

H2b. The higher the emotionality score, the less likely the leader is to propose business model adaptation in the domain of potential loss.

\section{Methods}

\subsection{Sample and data collection}

We distributed the survey to 385 randomly selected Scandinavian middle managers, top managers, and chief executive officers in various sectors. Of these, 134 participated, and after removing outliers and unfinished responses, 95 useful responses remained (26\% women and $74 \%$ men). A significant percentage (46\%) were aged $45-54$ years; most others were in the age groups 35-44 years (21\%) and 55-64 years (23\%). Almost all the responses (94\%) were 
from individuals in the private sector. The industries addressed included wholesale/retail trade, manufacture, maintenance, and construction. We did not collect information about nationalities, but all the participants spoke Norwegian and worked in Norwegian firms, so it is realistic to assume that most of the participants had Norwegian origins. The experiment consisted of two parts, the personality test and the field experiment, counterbalanced such that half the participants started with the personality test and the other half started with the field experiment.

\subsection{The personality test}

We administered the 60-item Hexaco personality test online to the participants. It included items such as "I would be quite bored by a visit to an art gallery"; "When working on something, I don't pay much attention to small details"; and "When it comes to physical danger, I am very fearful". All items used the following 5-point Likert scale: $1=$ "Strongly agree", 2 = "Agree", 3 = "Neutral (Neither agree nor disagree)", 4 = "Disagree", and $5=$ “Strongly disagree" (Ashton \& Lee, 2009).

\subsection{The field experiment}

The field experiment was conducted as an online study. This implies that all the stimulus material was administered electronically to participants. Since there is not yet a validated measurement scale available to measure business model adaptation, our measurement was closely aligned to the core features of the business model (Clauss, 2016): (1) the value proposition, (2) choice of target customer, (3) the structure of the value delivery and (4) the value capture mechanisms.

For the business model adaptation experiment, participants answered questions adapted and adjusted from Saebi et al.'s (2017) article on business model adaptation and risk domains, a 2010 survey of Norwegian firms after the financial crisis. Because "business model 
adaptation" is still a new term and measurement methods are not yet established, we deemed it appropriate to base the experiment on this survey.

Participants first chose at least two relevant external changes that their firm had experienced or was currently experiencing from the following list: changes in customer preferences, changes in supplier power, changes in technology, and changes in the competitive environment. We chose these external changes in line with the drivers of business model adaptation presented in Section 1 and Saebi et al.'s (2017) study. For each of the chosen external changes, participants viewed four replicates of scenarios of risk, developed using prospect theory, and were asked to make decisions based on these. The scenario with the least risk had a sure gain of 50 monetary units if no change was made and an uncertain expected gain of 80 monetary units if any changes were made. The riskiest scenario had an inevitable loss of 50 monetary units if no changes were made and an uncertain expected loss of 125 monetary units if changes were made. The scenarios were designed to measure participants' reactions to scenarios of potential high gain, low gain, low loss, and high loss; in other words, there were two replicates for each of the domains potential gain and potential loss.

\section{High Gain}

No change: $100 \%$ chance of gaining 50 monetary units

All other options: $90 \%$ chance of gaining 100 monetary units, $10 \%$ chance of losing 100 monetary units.

\section{Low gain}

No change: $100 \%$ chance of gaining 50 monetary units

All other options: $60 \%$ chance of gaining 100 monetary units, $40 \%$ chance of losing 100 monetary units. 


\section{High Loss}

No change: $100 \%$ chance of losing 50 monetary units

All other options: $10 \%$ chance of gaining 100 monetary units, $90 \%$ chance of losing 150 monetary units.

\section{Low Loss}

No change: $100 \%$ chance of losing 50 monetary units

All other options: $40 \%$ chance of gaining 100 monetary units, $60 \%$ chance of losing 100 monetary units

The experiment was designed so that the more risk the participants wanted to take, the more business model adaptation changes they could choose. Making choices in both domains ensured that we collected sufficient data in the gain context, which was lacking in Saebi et al.'s (2017) study. To simplify the experiment, we reduced Saebi et al.'s nine business model adaptation options to seven. One option was to do nothing, and the remaining six were practical and general options that could be applied to the chosen external changes (change number of products or services, change prize of products or services, increase sales efforts toward new customers or customers abroad, adjust relationships toward suppliers and/or partners, reorganize the organization).

\section{Results}

\subsection{Repeated measures analysis of variance to test $\mathrm{H} 1$}

In a one-way repeated measure analysis of variance, participants were exposed to the same experimental conditions (gains/losses), and the dependent variable had the characteristics of a continuous variable (business model adaptation). Thus, the data in the business model adaptation variables were considered sufficiently continuous, and we regard the necessary conditions to be met. 
We compared participants' business model adaptation - that is, the average changes made in the two domains - to determine whether significant differences were present between how many business model adaptation changes the participants chose in the domains. We measured differences between the main domains, potential gain, and potential loss (Potential gain, $M=$ 4,76, $S D=1,76, N=95$; Potential loss, $M=3,45, S D=2,13, N=95)$.. We observed a significant effect for the domains (Wilks' lambda $=.72, F=36.78, p<.001$ ). The effect provides support for $\mathrm{H} 1$ : business model adaptation was significantly higher in the domain of potential gain than in the domain of potential loss.

\subsection{Regression analysis to test $\mathrm{H} 2$}

Before performing the regression analysis, we considered some prerequisites. We deemed the sample size of 95 adequate, as it is within the minimum of accepted cases when considering the number of independent variables (Tabachnick \& Fidell, 1989). We next examined the correlation between the independent variables and observed some correlation between the personality trait variables extraversion and emotionality $(p=.4 \%)$. We tested for multicollinearity and found that all tolerance levels were far higher than .20 and all variance inflation factors were lower than 5, which indicates no multicollinearity (Christophersen, 2006). As stated in Section 2.1, we removed some outliers found in the initial data screening. We next screened for multivariate outliers by examining the Mahalanobis distance scores, and Cook's distance scores indicated none. Residuals and scatterplots indicated that the linearity assumptions were supported, and we deemed the assumption of homoscedasticity satisfied using the same method. We observed a moderate deviation from normality, but we deemed it not severe enough to deny the assumption of normality for the variables (Christophersen, 2006). 


\subsection{Predicting business model adaptation in the domain of potential gain}

Table 1 shows the predictive effect of the control variables (age, gender, managerial level, and number of years in the position) and the emotionality trait on business model adaptation in the domain of potential gain. The dependent variable in this regression is total gain - that is, the average changes made per external change in the domain of potential gain. Step 1 of the analysis shows that one of the control variables, gender, contributed significantly to the variance in the dependent variable, and therefore we retained it in hierarchical regression analysis. The other three control variables displayed no significant correlation, so we excluded them from the ensuing analysis to prevent a reduction of the significance of the regression model due to a decline in the degrees of freedom by including a higher number of nonrelevant, independent variables.

In step 2 of the analysis, we found that emotionality contributed significantly to the regression model, accounting for a further $4 \%$ of the variation in business model adaptation in the domain of potential gain. The effect was significant at the $1 \%$ level $(p=.010)$. Gender and emotionality were significant predictors of business model adaptation in the domain of potential gain. In total, the variables accounted for $10.5 \%$ of the variance. These results suggest support for $\mathrm{H} 2 \mathrm{a}$, that high emotionality makes business model adaptation less likely in the domain of potential gain. We also observed a positive, significant relationship between business model adaptation and gender $(p=.018)$, which indicates that the female participants were more inclined to choose business model adaptation changes than male participants.

\section{Table 1 about here}

\subsection{Predicting business model adaptation in the domain of potential loss}

Table 2 displays the predictive effect of the control variables (age, gender, managerial level, and number of years in the position) and emotionality on business model adaptation in the 
domain of potential loss. The dependent variable in this regression is total loss - that is, the average changes made per external change in the domain of potential loss. The analysis shows that the control variables made no significant contribution, so to avoid a reduction of significance, we excluded them from the hierarchical analysis. The next step reveals that emotionality did not contribute any significant variance in the dependent variable. The results of the analysis do not provide support for the proposed hypothesis (H2b) in the loss context.

\section{$\underline{\text { Table } 2 \text { about here }}$}

\section{Discussion}

\subsection{Theoretical implications}

Threat-rigidity theory has found support in much recent research. For example, studies show that threats leading to a reduction in control encourage more internally directed actions, in line with threat-rigidity theory (Chattopadhyay \& Huber, 2001), and researchers studying acquisitions have found similar results (Meschi \& Métais, 2015). Mcmanus and Sharfman (2017) show that when acquisitions were framed as threats, firms paid lower premiums; that is, they chose a less risky strategy. Tsai and Luan (2016) find that firm performance, risk taking capabilities, and their interaction positively correlate with risk taking, again supporting the threat-rigidity argument. As these and the examples in Section 1 indicate, research shows equivocal results when attempting to predict firm risk behaviour. Our study provides additional proof of threat-rigidity theory, suggesting that managers are more concerned with the possibility of downside outcomes than upside outcomes as risk (see also Selart, Johansen $\&$ Nesse, 2013). According to threat-rigidity theory, one important reason for this perception is that external threats induce adversity, which in turn sets organizational change in motion. 
Such change is biased by the organization's responses as structured by group interaction, formal information systems, core cultural rules, past organizational experiences as well as the adaptation of other organizations' solutions (Ocasio, 1993).

A neglected problem with individual-level Prospect Theory is that it is often overextended to organizational-level research (Shimizu, 2007). As a result, it does not incorporate the complex nature of "real" choices in organizations. This would require examining the theory's assumptions and incorporating the unique factors at that level, such as resource availability within an organization.

Another important contribution of this study pertains to the impact of emotionality on the relationship between risk perception and business model adaptation. The observed significant, negative correlation between emotionality and business model adaptation in the gain context contributes to the understanding of the trait's impact on risk taking and indicates potentially large significant effects of personality traits on business model adaptation.

Although we observed no significant findings on emotionality's impact in the loss context, the findings in the gain context accentuate the importance of this personality trait when potentially large payoffs can be achieved if risky decisions are made. The risk aversion displayed by participants with high emotionality scores in our experiment is in line with many previous contributions. Other studies show that emotionality is associated with less risk taking in the domains of both potential gain and potential loss (Weller \& Tikir, 2011; Weller \& Thulin, 2012). Studies using the Hexaco model show mostly significant results when testing for correlations between emotionality and risk taking. As touched on in Section 1.3, the Hexaco emotionality trait has slightly more complex properties than neuroticism. Individual differences such as anxiety, sentimentality, and empathy versus fearlessness, detachment, and independence are assigned to the emotionality trait in the Hexaco model (de Vries, et al., 2009; 
Weller \& Thulin, 2012). Including these traits can help explain why emotional individuals score lower on risk-taking behaviour such as business model adaptation.

Furthermore, risk taking and, by extension, business model adaptation are influenced by individuals' risk perception and propensity to take risks. Sjöberg and Wåhlberg (2002), referred to in Fyhri and Backer-Grønsdahl (2012), find that neurotic people perceive risk to be higher than emotionally stable individuals. Moreover, Oehler et al. (2018), using the fivefactor model of personality, find that neuroticism is related to high risk aversion in undergraduate business students. Weller and Thulin (2012) also link emotionality to accentuated perceptions of risk. The rigid approach to risk taking and business model adaptation displayed by the field experiment participants with high emotionality scores is therefore in line with much of the previous literature on the topic. In summary, in contrast with previous research in which evidence of the effect of emotionality and its corresponding fivefactor model trait is somewhat equivocal, this study contributes further proof of the negative relationship between managers' level of emotionality and their propensity to adapt business models and take risks.

\subsection{Practical implications}

In addition to the theoretical implications of our study, the results provide informational value for practitioners. The study provides further understanding of the business model adaptation concept and its applicability, as well as how personality traits can predict inclination to adapt the business model in different risk domains. The results are of particular value to firms aiming to create sustained competitive advantage and continuously capture and develop value in their environments, most notably due to the main finding of the study on the impact of emotionality on business model adaptation. 
Moreover, the results of this study indicate that there are valid applications of personality tests. Managers without the skill or willingness to adapt a business model can act as barriers to change in firms (Massa \& Tucci, 2013), and one reason they may do so is a high emotionality score. Entrepreneurs and recruiters can use this knowledge to review emotionality scores of applicants in jobs in which risk taking and an inclination to adapt the business model when necessary are of importance. Knowledge about the impact of personality traits is also useful when electing members for top management teams, as it is often this team that determines if and when a business model is ultimately changed (Teece, 2018). Top management teams are considered essential to eliminate barriers to change (Anyanwu, 2016). As a focus on business model adaptation is crucial for continuous performance growth and sustainable competitive advantage, considering applicant personality traits when making hiring decisions can be an important source of competitive advantage for firms.

Firms aiming to enhance their performance may therefore benefit from managers and top management team members with lower scores on the emotionality trait, as they are more likely inclined to adapt the business model. Consulting less emotional managers with an inclination to adapt and innovate the business model may also be an important tool for firms aiming to use business model adaptation as a competitive advantage. Consulting managers and top management teams with appropriate personality traits to be prepared for and respond to competitor business model adaptation may therefore be crucial for firms' long-term survival.

As high emotionality in managers leads to them being less willing to adapt the business model when there is a potential for future gain, highly emotional managers may have a negative effect for firms trying to achieve sustained competitive advantage. Therefore, the main practical implication of this study is that a deliberate recruitment strategy of managers in firms, in which personality traits of managers also facilitate business model adaptation, is important if firms want to use business model adaptation as a competitive tool. 


\subsection{Limitations}

Our data are based on single respondents in each firm, collected at one point in time, using one common method of data collection. Each of these weaknesses could be the source of potential biases. We hence applied ex ante remedies to control potential biases through the design of the study's procedures (Podsakoff et al., 2003; Chang et al 2010). For example, we took some measures before the data collection to prevent common method bias, most notably counterbalancing the order of the emotionality test and the business model adaptation experiment. Furthermore, the experiment presented the risk scenarios randomly, not in order of risk. Finally, we assured participants that their answers were anonymous, which should have reduced their evaluation apprehension (Podsakoff et al., 2003).

We also used ex post remedies to address common method bias in the statistical analysis of the data. One of the most popular ways to test for common method variance (CMV) is Harman's test, which measures how much of the variance one variable is accountable for. Running this test on the data returned a score of $23 \%$, which signified an acceptably low CMV. Many researchers recommend statistical methods of testing for CMV that are more sophisticated (Podsakoff et al, 2003), but Harman's test is widely considered a sufficient indication that CMV is not a serious concern.

In addition, we used questions similar to Saebi et al.'s (2017), which provides our study with a higher test-retest reliability than if the questions had been developed from scratch. In other words, the field experiment was based on existing research on business model adaptation and its drivers (Saebi, et al., 2017),

A potential weakness related to validity is that we applied a rather limited sample (134 Scandinavian managers) drawn from a particular geographical area. Yet, we secured that the sample was representative of the population to which we wished to generalize the findings. In 
addition it was within the minimum of accepted cases when considering the number of independent variables (Tabachnick \& Fidell, 1989)

\section{Conclusion}

We found that, in general, managers participating in a field experiment are more risk seeking in the gain scenarios than in the loss scenarios. Furthermore, our data show that managerial emotionality relates more to risk aversion than to risk seeking in the domain of potential gains. Both these results are in line with threat-rigidity theory, which stipulates that threats from the environment will lead to inward-looking conservative behaviour among managers and to a reliance on routines. High emotionality tends to increase conservatism in risky situations such as business model adaptations. Therefore, a practical implication of our results is that firms might consider refraining from hiring people with high scores on the emotionality trait to their top management teams. 


\section{References}

Achtenhagen, L., Melin, L. \& Naldi, L., (2013). Dynamics of Business Models - Strategizing, Critical Capabilities and Activities for Sustained Value Creation. Long Range Planning, Volume 46, pp. 427-442.

Andries, P., Debackere, K. \& Looy, B. V., (2013). Simultaneous Experimentation as a Learning Strategy: Business Model Development Under Uncertainty. Strategic Entrepreneurship Journal, Volume 7, pp. 288-310.

Anyanwu, C. (2016). Dynamic entrepreneurial and managerial role in the fron end loading (FEL): Phase for sensing and seizing emerging technologies. Management, 6, 146-157.

Ashton, M. C. \& Lee, K., (2007). Empirical, Theoretical, and Practical Advantages of the Hexaco Model of Personality Structure. Personality and Social Psychology Review, 11(2), pp. 150-166.

Bashir, M., \& Verma, R. (2019). Internal factors \& consequences of business model innovation. Management Decision, 57, 262-290

Bromiley, P., Miller, K. D., \& Rau, D. (2001). Risk in strategic management research. In M. A. Hitt, E. R. Freeman., \& J. S. Harrison (Eds.), Handbook of Strategic Management, 259289. Oxford: Blackwell

Casadesus-Masanell, R. \& Zhu, F., (2013). Business Model Innovation and Competitive Imitation: The Case of Sponsor-Based Business Models. Strategic Management Journal, Volume 34, pp. 464-482.

Cavalcante, S. A., (2014). Preparing for business model change: the "pre-stage" finding. Journal of Management \& Governance, Volume 18, pp. 449-469.

Cavalcante, S., Kesting, P. \& Ulhøi, J., (2011). Business model dynamics and innovation: (re)establishing the missing linkages. Management Decision, 49(8), pp. 1327-1342. 
Chang, S. J., van Witteloostuijn, A., \& Eden, L. (2010). From the Editors: Common method variance in international business research. Journal of International Business Studies, 41, 78-184.

Chattopadhyay, P. \& Huber, G. P., (2001). Organizational Action in Response to Threats and Opportunities. The Academy of Management Journal, October, 44(5), pp. 937-955.

Chesbrough, H. (2010). Business model innovation: Opportunities and barriers. Long Range Planning, 43, 216-226.

Christophersen, K.-A., (2006). Databehandling og statistisk analyse med SPSS. Oslo: Unipub.

Clauss, T. (2016). Measuring business model innovatiuon: conceptualization, scale development, and proof of performance. $R \& D$ Management, 47, 385-413.

de Vries, R. E., de Vries, A. \& Feij, J. A., (2009). Sensation seeking, risk-taking, and the Hexaco model of personality. Personality and Individual Differences, Volume 47, pp. 536540.

Demil, B. \& Lecocq, X., (2010). Business Model Evolution: In Search of Dynamic Consistency. Long Range Planning, Volume 43, pp. 227-247.

Doz, Y. L. \& Kosonen, M., (2010). Embedding Strategic Agility: A Leadership Agenda for Accelerating Business Model Renewal. Long Range Planning, Volume 43, pp. 370-382.

Ferreira, F. N. H., Proença, F. J., Spencer, R. \& Cova, B., (2013). The transition from products to solutions: External business model fit and dynamics. Volume 42, pp. 1093-1101.

Fyhri, A. \& Backer-Grøndahl, A., (2012). Personality and risk perception in transport. Accident Analysis and Prevention, Volume 49, pp. 470-475.

Judge, T. A., Bono, J. E., Ilies, R. \& Gerhardt, M. W., (2002). Personality and Leadership: A Qualitative and Quantitative Review. Journal of Applied Psychology, 87(4), pp. 765-780. 
Judge, T. A. et al., (2013). Hierarchical Representations of the Five-Factor Model of Personality in Predicting Job Performance: Integrating Three Organizing Frameworks With Two Theoretical Perspectives. Journal of Applied Psychology, September, 98(6).

Lee, K. \& Ashton, M. C., (2013). The H Factor of Personality: Why Some People Are Manipulative, Self-Entitled, Materialistic, and Exploitive-And Why It Matters for Everyone. s.1.:Wilfrid Laurier University Press.

Massa, L., \& Tucci, C. L. (2013). Business model innovation. In M. Dodgson, D. M. Gamm and N. Phillips (Eds.), The Oxford Handbook of Innovation Management. Oxford: Oxford University Press.

McCrae, R. R. \& Costa, P. T., (1987). Validation of the Five-Factor Model of Personality Across Instruments and Observers. Journal of Personality and Social Psychology, 52(1), pp. 81-90.

McGrath, R. G., (2010). Business Models: A Discovery Driven Approach. Long Range Planning, Volume 43, pp. 247-261.

Mcmanus, B. \& Sharfman, M. P., (2017). The impact of framing on acquisition premiums. Academy of Management Annual Meeting Proceedings, January, Volume 1.

Meschi, P.-X. \& Métais, E., (2015). Too Big to Learn: The Effects of Major Acquisition Failures on Subsequent Acquisition Divestment. British Journal of Management, 8 April, 26(3), pp. 408-423.

Miller, K., McAdam, M. \& McAdam, R., (2014). The changing university business model: a stakeholder perspective. $R \& D$ Management, 44(3), pp. 265-287.

Ocasio, W. (1993). The structuring of organizational attention and the enactment of economic adversity: A reconciliation of theories of failure, induced change and threatrigidity. Working papers 3577-93. Massachusetts Institute of Technology (MIT), Sloan School of Management. 
Oehler, A., Wendt, S., Wedlich, F., \& Horn, M. (2018). Investors' personality influences investment decisions: Experimental evidence on extraversion and neuroticism. Journal of Behavioral Finance, 19, 30-48.

Osterwalder, A. (2004). The Business Model Ontology: A Proposition in a Design Science Approach. Dissertation. Université de Lausanne, Ecole des Hautes Etudes Commerciales.

Osterwalder, A., \& Pigneur, Y. (2010). Business Model Generation: A Handbook for Visionaries, Game Changers, and Challengers. London: Wiley.

Pateli, A. G. \& Giaglis, G. M., (2005). Technology innovation-induced business model change: a contingency approach. Journal of Organizational Change Management, 18(2), pp. 167-183.

Podsakoff, P. M., MacKenzie, S. B., Lee, J. Y., \& Podsakoff, N. P. (2003). Common method biases in behavioral research: A critical review of the literature and recommended remedies. Journal of Applied Psychology, 88, 879-903.

Saebi, T., Lien, L. \& Foss, N. J., (2017). What Drives Business Model Adaptation? The Impact of Opportunities, Threats and Strategic Orientation. Long Range Planning, 50, 567-581.

Selart, M. (2010). A Leadership Perspective on Decision Making: Oslo: Cappelen Damm.

Selart, M., Johansen, S. T., \& Nesse, S. (2013). Employee reactions to leader-initiated crisis preparation: Core dimensions. Journal of Business Ethics, 116, 96-106.

Shimizu, K., (2007). Prospect Theory, Behavioral Theory, and the Threat-Rigidity Thesis: Combinative Effects on Organizational Decisions to Divest Formerly Acquired Units. Academy of Management, 50(6), pp. 1495-1514.

Sjöberg, L., \& af Wåhlberg, A. (2002). Risk perception and new age beliefs. Risk Analysis $22,751-764$.

Sosna, M., Trevinyo-Rodriguez, R. N. \& Velamuri, S. R., (2010). Business Model Innovation through Trial-and-Error Learning: The Naturhouse Case. Long Range Planning, Volume 43, pp. 383-407. 
Staw, B. M., Sandelands, L. E. \& Dutton, J. E., (1981). Threat Rigidity Effects in Organizational Behavior: A Multilevel Analysis. Administrative Science Quarterly, 26(4), pp. 501-524.

Tabachnick, B. G. \& Fidell, L. S., (1989). Using Multivariate Statistic. s.l.:Harpercollins College Div.

Teece, D. J., (2010). Business Models, Business Strategy and Innovation. Long Range Planning, Volume 43, pp. 172-194.

Trimpop, R. M., (1994). Chapter 1: What Is Risk Taking Behavior. The Psychology of Risk Taking Behavior, Volume 107, pp. iii-xxv, 1-386.

Tsai, H.-F. \& Luan, C.-J., (2016). What makes firms embrace risks? A risk-taking capability perspective. Business Research Quarterly, Volume 19, pp. 219-231.

Voelpel, S. C., Leibold, M. \& Tekie, E. B., (2004). The wheel of business model reinvention: how to reshape your business model to leapfrog competitors. Journal of Change Management, September, 4(3), pp. 259-276.

Weller, J. A. \& Thulin, E. W., (2012). Do honest people take fewer risks? Personality correlates of risk-taking to achieve gains and avoid losses in HEXACO space. Personality and Individual Differences, Volume 53, pp. 923-926.

Weller, J. A. \& Tikir, A., (2011). Predicting domain-specific risk taking with the HEXACO personality structure.. Journal of Behavioral Decision Making, April, 24(2), pp. 180-201.

Zott, C., \& Amit, R. H. (2010). Business model design: An activity system perspective. Long Range Planning, 43, 216-226

Zott, C., Amit, R. \& Massa, L., (2011). The Business Model: Recent Development and Future Research. Journal of Management, 37(4), pp. 1019-1042. 


\section{Table 1}

Summary of hierarchical regression analysis for variables predicting business model adaptation in the domain of potential gains.

\begin{tabular}{|c|c|c|}
\hline Variable & Step 1 & Step 2 \\
\hline Age & .08 & \\
\hline Gender & $.20^{* *}$ & $.24^{* *}$ \\
\hline Manager level & .09 & \\
\hline Years in position & -.16 & \\
\hline Emotionality & & $-.26^{* * *}$ \\
\hline $\mathrm{R}^{2}$ & .07 & .11 \\
\hline Adjusted $\mathrm{R}^{2}$ & .02 & .09 \\
\hline$\Delta \mathrm{R}^{2}$ & & .04 \\
\hline$\Delta \mathrm{F}$ & 1.66 & $3,84^{*}$ \\
\hline
\end{tabular}




\section{Table 2}

Summary of hierarchical regression analysis for variables predicting business model adaptation in the domain of potential losses.

\begin{tabular}{|c|c|c|}
\hline Variable & Step 1 & Step 2 \\
\hline Age & -.03 & \\
\hline Gender & .02 & \\
\hline Manager level & -.06 & \\
\hline Years in position & -.09 & \\
\hline Emotionality & & .04 \\
\hline $\mathrm{R}^{2}$ & .04 & .00 \\
\hline Adjusted $\mathrm{R}^{2}$ & .00 & -.01 \\
\hline$\Delta \mathrm{R}^{2}$ & & -.04 \\
\hline$\Delta \mathrm{F}$ & 1.05 & -.20 \\
\hline
\end{tabular}

$\mathrm{N}=100,{ }^{*} p>.10, * * p<.05, * * * p<.01$.

Note: Standard regression coefficients are shown. 